\title{
An Investigation on the Dominant and Preferred Organisational Culture Construct at a Selected Higher Education Institution in South Africa
}

\author{
W Ndlovu a ${ }^{*}$, H Ngirande a, TS Setati a, JJ Zaaiman ${ }^{\text {b }}$, MP Rachidi ${ }^{\mathrm{c}}$ \\ a Department of Human Resource Management \& Labour Relations, University of Venda. Thohoyandou. South Africa. \\ b Department of Operations Management, University of Venda. Thohoyandou. South Africa. \\ c Department of Human Resource Management, University of Venda. Thohoyandou. South Africa. \\ ${ }^{*}$ Corresponding author's email address: wiseman.ndlovu@outlook.com.
}

\section{A R T I C L E I N F O}

Received: 14-05-2016

Accepted: $13-06-2016$

Available online: 29-06-2016

Keywords:

Higher education institution;

Organisational behaviour;

Organisational culture.

\section{A B S T R A C T}

The aim of the study was to investigate the dominant and preferred organisational culture at a higher education institution in South Africa and how organisational culture influences the organisational behaviour. The study employed a quantitative research design and 30 employees were randomly selected from two groups of non-academic and academic staff members of a selected school at the institution. A structured questionnaire was utilised to solicit information regarding the dominant and preferred organisational culture at the institution from the participants. The Statistical Package of Social Sciences (SPSS) version 2013 was used to determine the preferred and existing culture through mean scores. The results revealed that a role culture was dominant in the institution whilst employees preferred a support culture. The study further revealed that organisational culture has a significant impact on numerous organisational processes, employees as well as organisational performance. In addition, the results showed that if employees have shared norms and are supported by the organisation, they can increase their performance towards achieving overall organisational goals. Thus, from the findings, the study recommends policy makers and decision makers in organisations to adopt support culture through providing support to their employees to achieve both personal and organisational goals.

JEL Classification:

(C) 2016 The Authors. This is an open access article under the terms of the Creative Commons Attribution License 4.0, which allows use, distribution and reproduction in any medium, provided the original work is properly cited.

DOI: http://dx.doi.org/10.18533/rss.v1i6.38.

\subsection{Introduction}

South African Higher Education Institutions (HEI) have the mandate of human resource development and capacitating the citizens with the necessary skills for social and economic development (Department of Higher Education and Training, 2012). The measure of success of these higher education institutions is based on students' success rate, graduation rate and weighted research output per academic staff member (Ministry of Education, 2002). Based on this criterion, a study conducted by the Ministry of Education (2002) revealed that the institution where the study was undertaken performed below the expectations in comparison to other higher education institutions (HEI) in South Africa. In addition, the ranking of the top universities in South Africa rated the institution as number $19^{\text {th }}$ out of 23 on the list. (Wikipedia accessed 12 May 2014).

University of Venda is one of the higher education institutions which was classified as a historically black institutions during the apartheid era. Higher education institutions have been targeted for transformation and aligning them with the former "White" higher education institutions (Ministry of Education, 2002). Since the 
enactment of the transformation charter for higher education institutions, most of these former bantu institutions have been lagging behind in terms of performance and meeting the expected culture of higher education institutions in general and have been plagued by a number of challenges such as lower graduation rates and poor research output per staff member (Kruger \& Ramdass, 2010).

To counter these challenges faced by the former Bantu higher education institutions, it will be of paramount importance to investigate if the way things are done in these institutions are related to preferred organisational culture. Preferred organsiational culture by employees will help and see employees realising their full potential and taking these higher education institutions to the envisaged path (transformation). Organisational culture is said to detect the way in which things are done in any organisation (Black, 2004). Therefore, if the culture is the most preferred by employees it will enhance individual performance and commitment to the organisation as they feel their needs and desires are met. Thus, the various organisational culture typologies were analysed and subsequently evaluated on how they affect organisational processes and activities based on the literature.

\subsection{The concept of organisational culture}

Hofstede (1980) defined organisational culture as the collective programming of the minds of individuals and it distinguishes one organisation from the other. Organisational culture can also be viewed as the careful gathering of standards and values that are common between individuals in a specific company which controls the way in which organisational members interact with one another in the organisation and outside the organisation (Black, 2004). Furthermore, Black (2004) pointed out that organisational values and beliefs, guidelines and expectations emanate and describe the accepted behaviours by different employees when faced with a certain situation. This implies that organisational culture is the way things are done in an organisation including the methods, processes and procedures to be followed.

Organisational culture impacts on decision making, promotion, people practices, and how the organisation responds to the external environment (Meijan, 2007). In a similar view, Martin (2005) further revealed that organisational culture is the key factor in the organisation as it drives its development and success. It is therefore important to identify the unique organisational culture as a particular organisation as organisation culture may impede or enhance performance of institutions.

According to Chatman and John (1994), organisational culture is influenced by different factors such as organisational history, main function, approach, size, place, running of the organisation the way people are led and the setting. Moreover, organisational culture is strongly influenced by its primary function and technology which detects the range and quality of clients or customers and type of clients or customers it attracts (Nel, et al., 2014). In addition to this, Nel et al. (2014) further stated that organisational culture is influenced mainly by the grouping of goals and subsequent strategies which will in turn affect organsaitional performance.

Rehman (2012) states that the effects of organisational culture on employee behaviour and performance was based on four key ideas of Bulach, Lunenburg and Potter (2012), which indicate that culture enables the employees to understand the history of the organisation and what is expected of them in terms of the behaviours. It also fosters commitment which enables employees to work towards achieving a common goal. In addition, the norms of culture can be used as the control tool for employees towards desired behaviours and against unwanted behaviours. Lastly, cultures can be directly related to higher performance and productivity more than others. In conclusion, Rehman (2012) indicated that organisations which know how to cultivate their culture in an operative way are highly likely to be better positioned in terms of production and good work life among workers.

Several organisational culture typologies have been identified over time and scholars have shown how they relate to the behaviour and performance of an organisation (Hofstede, 2005; Kandula, 2006; Ng'ang'a \& Nyongesa, 2012; Suppiah \& Sandhu, 2012; Leskaj, Lipi \& Ramaj, 2013). These typologies include, clan, bureaucratic, entrepreneurial, market, role, power, achievement and support culture (Harrison \& Stokes, 1992; Hellriegel et al., 2004). This study was based on the Harrison \& Stokes (1992)'s culture typologies.

\subsection{Harrison and Stokes's organisational culture typologies}

According to Harrison \& Stokes (1992), there are various types of cultures which are power, role, achievement, and support orientation. These culture types are briefly explained below.

\section{$3.1 \quad$ Power culture}


Power culture is commonly found in small businesses, as control of the organisation is centred on one person (Martin, 2005). All the crucial decisions are centred on the person in charge of the whole organisation and that particular person has power and absolute authority in almost all matters. Harrison \& Stokes (1992) state that an institution that is power cultured is based on disproportion when it comes to resource allocation or access. Those in power tend to use the available resources to manipulate and control others. The most important advantage of power culture is its adaptability to change and quick reaction to external forces or environment. Thus its success is strongly reliant on the capabilities of those in charge or leaders (Brown, 1995; Martin, 2005).

\subsection{Role culture}

Role culture is focused on the presence of processes, protocols and rules with clear definition of what an employee has to do (Harrison \& Stokes, 1992; Martin, 2005). Power struggles are watered-down by the rules. Under this type of culture the administrative work environment, control and accountability are passed downwards to the bottom levels and all the levels of the institution have a clear source of control and the work is expected to be continuously done without being directly controlled by the top management (Harrison \& Stokes 1992). Role culture has the advantage that workers of a company can allocate extra effort in executing their duties and tasks (Harmse, 2001). On the other hand, the drawback of this cultural type is the fact that workers are presumably untrustworthy. Also employees at the bottom of the hierarchy are allowed to practice self-rule and will (Harrison \& Stokes 1992).

\subsection{Achievement culture}

Achievement culture gives workers mutual vision and determination in the organisation (Harrison \& Stokes 1992). This is the mutual vision and determination shared by members of the organisation to attract and motivate them in attaining or meeting the goals of the institution (Harrison \& Stokes, 1992). Achievement culture has an advantage of that employees willingly give more or go an extra mile in their organisations because employees contribute more freely in reaction to their dedication to the common goals and purpose, and consequently, the whole institution succeed. An achievement orientation organisation has employees who are enthusiastic, energetic, and involved (Harmse, 2001).

\subsection{Support culture}

Support culture is grounded on common belief amongst the employees and the institution (Harrison \& Stokes 1992). Workers that work in a support-orientated organisation view the organisation as caring, and values them as human beings, not as machines employed to complete tasks (Harrison \& Stokes 1992). An organisation with a support culture has a caring and warm atmosphere, where employees have a sense of belonging thus enhancing commitment and hence high contribution to the organisation which will translate to high performance and development (Harmse, 2001; Meijan, 2007). The benefits of the support-orientated organisation are that workers back up one another for the success of the organisation, and the fact that there is high team loyalty and contributes to high performance and enthusiasm is high (Harrison \& Stokes, 1992). The demerit of the support culture is that the organisation tends to have conflicts and difficult matters/problems are often swept under the carpet (Harrison \& Stokes, 1992).

If the dominant organisational culture is not the preferred organisational culture studies have shown that it breeds resistance to change in the future of the organisation (Kandula, 2006; Suppiah \& Sandhu, 2012). As defined, organisational culture determines how things are done in an organisation thus processes and procedures determine organisational culture. Therefore, if the organisational culture (processes and procedures) is not clear and well defined it will result in decreased morale and poor performance by employees (Prosci, 2010). On the other hand, if the dominant culture is the preferred organisational culture by employees it will enhance performance and commitment by employees (Hofstede, 2005). Furthermore, the study by Olanipekun, Aje \& Abiola-Falemu (2013) revealed that with the appropriate organisational culture thus clear objectives, norms and values it is possible to enhance the performance of the organisation.

A review of several studies indicated that organisational culture gives guidelines on how operations in an organisation will be executed; therefore culture is the main driver to organisational performance and development (Hofstede, 2005; Kandula, 2006; Ng'ang'a \& Nyongesa, 2012; Leskaj, Lipi \& Ramaj, 2013; Olanipekun, Aje \& Abiola-Falemu, 2013).

Several studies have been conducted on organisational culture and its influence on various factors in different sectors, including commitment of employees in the motor manufacturing company (Manetje \& Martins, 2009) organisational performance and employee performance of educational institutions in Kenya (Ng'ang'a \& 
Nyongesa, 2012). However, little information is known regarding an inquiry on the dominant and preferred organisational culture in South African higher education institutions. Therefore this study seeks to explore the dominant and preferred organisational culture construct that exists at a selected South African higher education institution.

\subsection{Objectives of the study}

The study was guided by the following objectives:

- To investigate the dominant and preferred organisational culture at a selected higher education institution in South Africa

- To establish which cultural typology is preferred at a selected higher education institution in South Africa.

This study endeavoured to assist in identifying the existing and preferred culture which help in closing the gap between the two therefore fuelling the transformation process of the higher education institution.

\subsection{Methodology}

The study employed a quantitative research design and made use of questionnaires to collect data from academic and non-academic staff members of a selected school at the University of Venda.

The researcher used a random sampling technique to determine the number of participants in the study. Random sampling eliminated biasness as each member within the selected school had an equal chance to be selected. To measure organisational culture (existing and preferred culture). Harrison and Stake's (1992) organisational culture questionnaire with 15 sub-statements was used. The instrument is composed of 4 subscales which are role, achievement, power, and support orientation. All the scales where measured on a 4 point Linkert Scale ranging from 1-4. Thus, $1=$ strongly agree and $4=$ strongly disagree.

Personal information of the respondents was analysed using descriptive statistics. Crosstabs analysis was used to determine the preferred culture by the participants. The above analyses were done making use of Statistical Package for the Social Sciences programme (IBM-SPSS, 2013).

In the analysis of this research data, simple frequency tables were used to summarise and understand the data (Punch, 1995). Punch (1995) stipulated that frequency tables describes the participants' scores in the distribution and are tabulated according to how many respondents achieve each score, or gave each response, or are classified into each category. The two sections of the questionnaire were analysed statistically using frequency distributions because the results can be shown as tables or as graphs, which allows results to be easily illustrated as well as enabling the investigator to have the basic idea of the features of the data (Punch 1995; Sekaran, 1992). Once the information was analysed using frequency tables, simple graphs were constructed and graphically represented (Milton, 1992).

Harrison and Stake (1992) organisational culture questionnaire has been confirmed in South Africa by scholars such as Grebe (1997), and Harmse (2001) and who established conventional outcomes with respects to the validity and reliability. Harrison and Stake (1992) tested the reliability of the instrument and found that the Cronbach's alpha coefficient was 0.90 for power culture, 0.64 for role culture, 0.86 for achievement culture and 0.87 for support culture. In the present study, the reliability of the culture questionnaire was tested and the results for Cronbach's alpha of existing and preferred culture are shown in table 1 and 2 below respectively.

\begin{tabular}{|c|c|c|c|}
\hline Scale & Cronbach's alpha (r) & Items & Interpretation \\
\hline Achievement & 0.491 & 15 & Poor \\
\hline Culture (EAC) & & & \\
\hline $\begin{array}{l}\text { Existing Power Culture } \\
\text { (EPC) }\end{array}$ & 0.644 & 15 & Acceptable \\
\hline Existing Role Culture (ERC) & 0.753 & 15 & Good \\
\hline $\begin{array}{l}\text { Existing Support Culture } \\
\text { (ESC) }\end{array}$ & 0.811 & 15 & Excellent \\
\hline Average & 0.675 & 15 & Good \\
\hline
\end{tabular}


Table 2: Reliability of the preferred organisational culture

\begin{tabular}{|c|c|c|c|}
\hline Scale & Cronbach's alpha (r) & Items & Interpretation \\
\hline Preferred Achievement Culture (PAC) & 0.825 & 15 & Good \\
\hline Preferred Power Culture (PPC) & 0.860 & 15 & Excellent \\
\hline Preferred Role Culture (PRC) & 0.721 & 15 & Good \\
\hline Preferred Support Culture (PSC) & 0.753 & 15 & Good \\
\hline Average & 0.790 & 15 & Good \\
\hline
\end{tabular}

Fifty questionnaires were distributed to the institution employees from both academic and non-academic of a selected school within the institution. From the 50 distributed questionnaires, 30 usable questionnaires were completed and returned after three weeks, representing a response rate $60 \%$.

The questionnaire did not ask the respondents to fill in their names, hence ensuring confidentiality of the participants. Furthermore, participants were informed that their participation is voluntary and should they not feel comfortable in answering some or the whole questionnaire they have the right not to. The sample was composed of $14(46,7 \%)$ respondents from academic staff and $16(53,3 \%)$ respondents from non-academic staff of a selected school.

\subsection{Results and discussions}

Out of the 50 questionnaires distributed only 30 participants responded with a large number of participants $9(30 \%)$ falling within 1-2 and 3-4 years of service at the institution, followed by 5-6 years of service 7(23, 3\%). The least number of participants $1(3.3 \%)$ had been working in the institution for less than a year. A large number of the participants were males and constitute a total number of $16(53,3 \%)$.

Results further revealed that a large number of participants 15(50\%) were between the ages of 31-40 years, and majority of participants 20(66.7\%) were in possession of a Post-Graduate Degree. Few employees were in possession of grade 12 certificate $1(3.3 \%)$ as their highest qualification.

As stated earlier to determine the culture profile in the study descriptive statistics was used, by calculating the mean scores of each organisational culture typology as identified by Harrison and Stoke (1992). The results of the cross tabs was tabulated and illustrated in table 3 below.

\begin{tabular}{|c|c|c|c|}
\hline \multicolumn{4}{|c|}{ Table 3: Overall organisational culture means scores } \\
\hline Type of Culture & Category & Mean & SD \\
\hline \multirow[t]{2}{*}{ Role Culture } & Existing & 47.48 & 2.544 \\
\hline & Preferred & 39.25 & 1.777 \\
\hline \multirow[t]{2}{*}{ Power Culture } & Existing & 42.29 & 3.680 \\
\hline & Preferred & 26.89 & 2.200 \\
\hline \multirow[t]{2}{*}{ Achievement Culture } & Existing & 33.97 & 3.784 \\
\hline & Preferred & 44.66 & 2.734 \\
\hline \multirow[t]{2}{*}{ Support Culture } & Existing & 35.04 & 3.717 \\
\hline & Preferred & 51.07 & 2.420 \\
\hline
\end{tabular}

Table 1 show the unique dominant and preferred organisational culture scales as analysed by use of mean scores. The mean scores shows that the most dominant/existing culture at Univen is role culture (47.48), followed by power culture (42.29), achievement culture (33.97) and support culture (35.04).

\section{Existing culture profile}

The result in Table 1 also show that the highest overall mean score for the existing/dominant culture across the organisational culture scales is the role culture which has a mean score of 47.48. This is an indication that employees at Univen believe that there is a greater emphasis on task completion. It is supported by the study by Hooijberg and Petrock (1993) which indicated that role culture can be linked with the bureaucratic culture. Hooijberg and Petrock (1993) further indicated that this type of culture has clearly defined tasks, responsibilities and authority. Given this, one can argue that employees believe that their duty is to follow company's rules, procedures and processes. In addition to this, role culture oriented organisations have spelt out responsibilities and there is usually a centralised source of control (Handy, 1993).

Role culture is closely related to the culture typology identified by Brown (1995) which places emphasis on the systems and procedures within the institution. This type of culture can typically be found in institutions of low risk environment, slow feedback and where the success of the organisation comes from much attention to detail. 
The absence or little of feedback in these types of organisations result in employees focusing more on how they perform tasks, as opposed to what task they perform. This might however lead to the poor outcomes or end product as they employees focus more on how the task is performed. In the case of higher education institutions it might result in unemployable graduates.

The results also shows that power culture has the second highest mean score (42.29). This implies that employees believe that the institution has centralised control. According to Martin (2005), organisations with power culture have sole authority or few individuals in power who try to control and influence employee behaviours and make important decisions. Thus the success of the higher education institutions depends strongly on the person/persons in positions of power and staff/employees are expected to report any problem that occurs in the workplace to that individual or small group of senior managers (Martin, 2005).

The strength of power culture is its ability to react to the changes since there are few sources of power which deal with change. A huge disadvantage of power culture is the fact that employees do not have much say and cannot ask their leaders even when they are doing wrong, and employees are also not inclined to give bad news to their supervisors or front-runners due to the consequences that might follow (Harrison, 1993).

Finally, the results show that there is little support and motivation for the respondents. This is indicated by the mean scores of support and achievement culture which are 35.04 and 33.97 respectively.

\section{Preferred culture profile}

In relation to the preferred culture, Table 1 support culture has shown the highest mean score of (51.07), followed by Achievement culture (44.66), Role culture (39.25) and Power culture (26.89). Preferred culture will probably help in answering the issue of slow development in HEI and fuel high performance. As stated earlier, Table 1 which shows that the most preferred culture is the support culture (51.07) followed by achievement culture (44.66). These scores indicate that respondents at the institution would want to have more of support culture as opposed to a power culture which has the least mean score of 26.89 as shown in the Table 1 . This can be deduced from the comparison of mean scores of existing culture and preferred culture. Thus respondents prefer support culture which is based on reciprocal trust and teamwork between the employees and the institution (Harrison, 1993; Harrison \& Stokes, 1992). Respondents would also want to be supported and be valued as the most important assets of the organisation. Harrison and Stokes (1992) also share the same sentiments by stating that employees who prefer to be treated and valued as human beings, not just as machines designed to produce output for the institution.

Support and achievement culture can be closely linked to entrepreneurial culture as identified by Hellriegel et al., (2004). The support and empowerment given to employees enhances the innovative and creative spirit in employees, such as better ways of teaching, new programs and greater cohesion within the team.

\section{Preferred organisational culture profile according to schools/departments.}

The researcher also wanted to establish if there is a relationship/difference between different sexes' view on the existing culture profile at the selected institution. To perform this a chi-square test of association was performed by cross tabulating two variables namely gender and existing culture to test whether there is any association. From the results a chi-square value of 12.2341 and 4 degrees of freedom with a probability value of 0.431 was found. Since the p-value is greater than 0.05 , it therefore means that there is no any association between gender and the existing culture as depicted in Table 2 below.

Table 4: Chi-Square test showing the association between gender and power culture

\begin{tabular}{lrrr}
\hline & Value & df & Sig. (2-sided) \\
\hline $\begin{array}{l}\text { Pearson Chi-Square } \\
\text { N of Valid Cases 30 }\end{array}$ & 12.2341 & 4 & 0.43103 \\
\hline
\end{tabular}

Table 5: Preferred culture according to academic/non-academic staff of a selected school

\begin{tabular}{lrr}
\hline Preferred culture & & Departments \\
\cline { 2 - 3 } & Academic staff & Non-academic staff \\
\hline Power & 0 & 0 \\
Achievement & 3 & 6 \\
Role oriented culture & 7 & 3 \\
Support & 4 & 7 \\
Total & 14 & 16 \\
\hline
\end{tabular}


Out of 14 participants from academic staff in a selected school, 7 chose role culture as the preferred culture followed by 4 for the Support culture and 3 for the Achievement culture as shown in table 3 above. Thus, the role culture is the most preferred culture followed by support culture at the institution where they fulfil themselves and are given the necessary support in order to reach organisational goals. In non-academic staff members, the most preferred culture is support culture depicting the need to provide support and assistance to the staff members. As indicated in table 3 above, non-academic staff in a selected school prefer the Achievement culture indicating that workers may have "higher order needs/higher level needs" that they have to satisfy, such as the need for self-fulfilment as suggested by Watson (2002). Respondents have shown that they prefer to become all they can be through individual accomplishment of challenging objectives that have been set.

Table 6: Differences between existing and preferred culture

\begin{tabular}{lrr}
\hline Cultural type & Differences between Mean scores & Difference \\
\hline Role Culture & $(47.48 E R C-39.25 P R C)$ & 8.23 \\
Power Culture & $42.29 \mathrm{EPC}-26.89 \mathrm{PPC}$ & 15.4 \\
Achievement Culture & $44.66 \mathrm{PAC}-33.97 \mathrm{EAC}$ & 16.03 \\
Support Culture & $51.07 \mathrm{PSC}-35.04 \mathrm{E}$ & 10.69 \\
\hline
\end{tabular}

In the above analysis it can be noted that there is no significant difference between the existing and preferred role and achievement culture at the institution as shown by 8.23 and 10.69 respectively, in the table 3 above. Thus, employees are quite happy with the strong emphasis on the task completion and their roles.

The significant difference was observed between the Support and Power culture. Employees seem to strongly dislike the existing power and support culture at the institution. The results indicate that employees would like to see the adjustments made in these two cultural typologies. Thus, more support culture nurtured and power culture reduced to lower levels.

\subsection{Limitations of the study}

The study had a number of challenges of which among them was the response rate of $60 \%$, thus only 30 questionnaires were collected out of 50 distributed questionnaires. This weakened the study findings as the sample size was limited and it compromised the representatively of the results. However, the researcher had to analyse the data according to the responses given by the respondents. In addition, the random selection of participants in the study per various departments made it easier for the study to bear much weight on its findings.

The study results can also be used to conduct other similar studies in higher education institutions. Thus, these results is worthwhile as the procedural and methodically selection to the participants was carefully considered to eliminate or limit possible bias with smaller samples.

\subsection{Conclusions and recommendations}

The study demonstrated that the most dominant culture at the institution under study is the role culture which has a weakness of rigidity and inflexibility thus slowing the transformation and change of the organisation. The Support culture as the preferred culture will see employees becoming proficient in their trade if they are given the necessary wings to fly that is the support they need. Furthermore, the Support culture enhances teamwork and collaboration which inspires idea sharing, innovation and creativity fuelling high performance and adaptability.

The study findings show that there is a gap between the existing and preferred institutional culture in the participating organisation. Since culture detects the behaviour of employees in an organisation, the institution may move from its current dominant culture closer to the one preferred by employees to enhance its performance and development.

Given these findings one can argue that culture plays a significant role in the current image of the organisation and its level of performance at both the employee and the institutional level. Therefore the need for the policy makers at the institution to consider a shift from the current culture profile to enhance and stimulate the behaviours of its employees in the process enhancing its performance.

\section{References}

Black, R. J. (2004). Organizational culture. Creating the influence needed for strategic success. Core DRAW. ISBN. 
Brown, A. D. (1995). Organisational culture. London, UK: Pitman Publishing. http://dx.doi.org/10.1177/017084069501600602

Bulach, C., Lunenburg, F. \& Potter (2012). Creating a future of high performing schools; a comprehensive approach to school reform (2 ed.). Lanham, MD: Rowan and Littlefield.

Chatman, J. \& John, K. (1994). Assessing the relationship between industry characteristics and organizational culture: How different can you be? Academy of Management Journal, 37, 522-553. http://dx.doi.org/10.2307/256699

Grebe, E. R. (1997).Culture as a transformative agent in a tertiary institution. Journal of Cross Cultural Psychology 38(1), 10-30.

Handy, C. (1993). Understanding Organisations. London, UK: Penguin.

Harmse, L. M. (2001).The influence of organisational culture on job satisfaction and organisational commitment. Unpublished thesis for Bachelor of Commerce, Port Elizabeth: University of Port Elizabeth.

Harrison, R. (1972). 'Understanding your organization's character' Harvard Business Review May-June

Harrison, R. (1993). Diagnosing organisational culture: Trainer's manual. New York: Pfeiffer and Company.

Harrison, R., \& Stokes, H. (1992). Diagnosing Organisational Culture. New York: Pfeiffer and Company.

Hellriegel, D., Jackson, S. E., Slocum, J., Staude, G., Amos, T., Klopper, H. B., Louw, L., \& Oosthuizen, T. (2004). Management (2nd ed.). Cape Town: Oxford University Press Southern Africa.

Hofstede, G. (1980). Culture's Consequences: International Differences in Work-Related Values. Beverly Hills, CA: Sage.

Hofstede, G. (2001). Culture's consequences: comparing Values, Behaviours, Institutions and Organisations Across Nations.

Hofstede, G. (2000). Culture's Consequences: International Differences in Work Related Values. Beverly Hills, CA: Sage Publications.

Hofstede, G. (2005). Culture's Consequences (2nd ed.). London, UK: SAGE Publication limited.

Kandula, S. R. (2006). Performance Management. New Delhi: Prentice Hall of India private limited.

Lim, B. (n.d.). Examining the Organisation Culture and Organisation Performance. Leadership \& Organisation Development Journal, 2, 16-21.

Leskaj, E., Lipi, I. \& Ramaj, R. (2013). Features of Organizational Culture and Their Impact on Banking System Performance. International Journal of Economic Practices and Theories, 3(4), 2247-7225.

Manetje, 0. \& Martins, N. (2009). The relationship between organisational culture and organisational commitment. Unpublished Thesis.

Ministry of Education. (2002). Transformation and Restructuring: A New Institutional Landscape for Higher Education. Department of Higher Education and Training.

Nel, P., Werner, A., Botha, C., Du Plessis, A., Mey, M., Ngalo, O., Poisat, P., \& Van Hoek, L. (2014). Human Resources Management, (9th ed.). Oxford, Southern Africa.

Ng'ang'a, J. M., \& Nyongesa, J. W. (2012). The Impact of Organisational Culture on Performance of Educational Institutions. International Journal of Business and Social Science, 3(8), 211-216.

Olanipekun, A., I. O, A., \& Abiola-Falemu, J. (2013). Effects of Organisational Culture on the Performance of Quantity Surveying Firms in Nigeria. International Journal of Humanities and Social Science, 3(5), 45 -60.

Prosci, (2010). Definition and scope of change management. Prosci change management webinars.

Punch, K. F. (2005). Introduction to Social Research: Quantitative and Qualitative Approaches (2nd ed.). London, UK: SAGE Publications Ltd.

Ranking of universities. (n.d). en.m.wikipedia.org//Rankings of universities in South Africa.

Rehman, U. E. (2012). Effects of organisational culture on organisational performance. VU Pakistan.

Sekaran, U. (1992). Research methods for business: A skill building approach (2nd ed). New York: John Wiley \& Sons.

Suppiah, V. \& Sandhu, M. S. (2012). Organisational Culture's Influence on Tacit Knowledge Sharing Behaviour. Journal of Knowledge Management, 15(3), 462-477. http://dx.doi.org/10.1108/13673271111137439

Van Stuyvesant Meijen, J. (2007). The influence of organisational culture on organisational commitment at a selected local municipality.

Watson, T. J. (2002). Organising and Managing work: Organisational, Managerial and Strategic Behaviour in Theory and Practice. Harlow: Pearson Education. 